Portland State University

PDXScholar

$5-1973$

\title{
A Cross-Class Survey of Synaesthesia in High School Students and its Biocultural Implications
}

Ina Jane Wundram

Portland State University

Follow this and additional works at: https://pdxscholar.library.pdx.edu/open_access_etds

Part of the Cognition and Perception Commons, and the Social and Cultural Anthropology Commons Let us know how access to this document benefits you.

Recommended Citation

Wundram, Ina Jane, "A Cross-Class Survey of Synaesthesia in High School Students and its Biocultural Implications" (1973). Dissertations and Theses. Paper 2156.

https://doi.org/10.15760/etd.2154

This Thesis is brought to you for free and open access. It has been accepted for inclusion in Dissertations and Theses by an authorized administrator of PDXScholar. Please contact us if we can make this document more accessible: pdxscholar@pdx.edu. 
AN ABSTRACT OF THE THESTS OF Ina Jane Wundram for the Master of Arts in Anthropology presented May, 1973.

Title: A Cross - Class Survey of Synaesthesia in High School Stadents and its Biocultural Implications.

APPROVED BY,MEMBERS OF THE THESIS COMMTTEE:

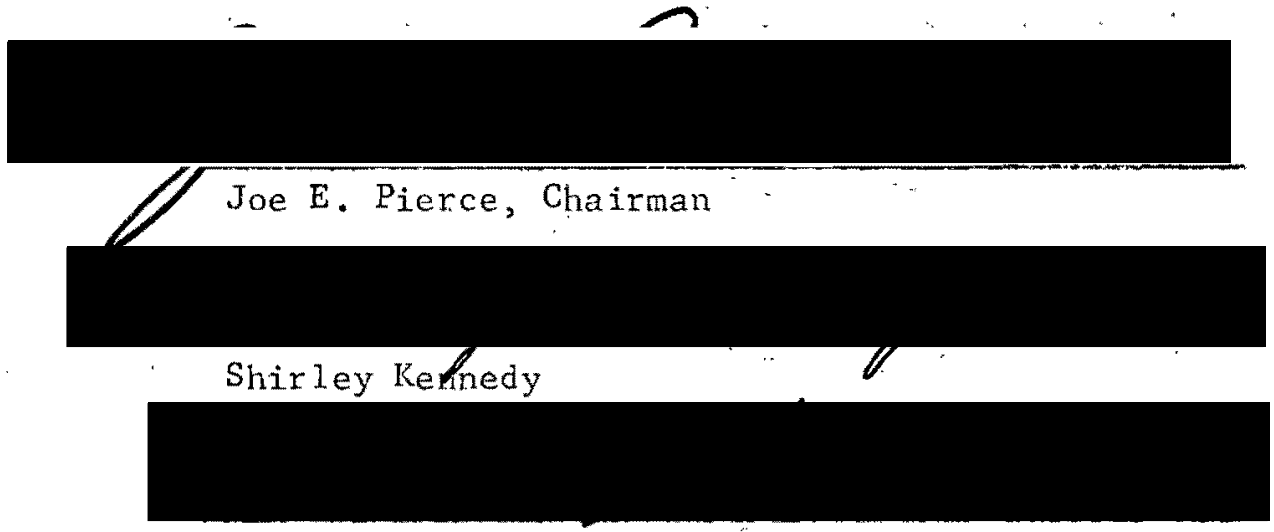

Daniel Scheans

It has been suggested in the literature that Syraesthesia, as an expression of syncretic thought, would be more common in non-Western than in Western cultures. Given the lack of availability of widely divergent cultural groups and the general lack of knowledge about the phenomenon, it was decided to study the possibility that synaesthesid in our society might be related to socio-economic ciass. A group of high school students from a broad range of socio-economic backgrounds was studied, and the results suggest that the occurrence of synaesthesia is not related to class. In addition, it was found that $50 \%$ of the 
sample tested were synaesthetic to some degree, an incidence higher than any reported previously for adults. The various types of synaesthesia are discussed in conjunction with a hypothetical neurophysiological basis for the phenomenon. It was found that about $60 \%$ of the synaesthetic subjects shoved evidence of incomplete cerebral dominance. However, no definite conclusions as to the causes of synaesthesia in adults could be determined from the observations made, and the questions raised by this study offer suggestions for future research into the problem. 
A CROSS - CLASS SURVEY OF SYNAESTHESIA IN HIGH SCHOOL STUDENTS

AND ITS BIOCULTURAL TMPLICATIONS

\author{
by \\ Ina Jane Wundram \\ A thesis submitted in partial fulfillment of the \\ requirements for the degree of
}

\author{
MASTER OF ARTS \\ in \\ ANTHROPOLOGY
}

Portland State University

1973 
TO THE OFFICE OF GRADUATE STUDIES AND RESEARCH:

The members of the Committee approve the thesis of

Ina Jane Wundram presented May 18, 1973.

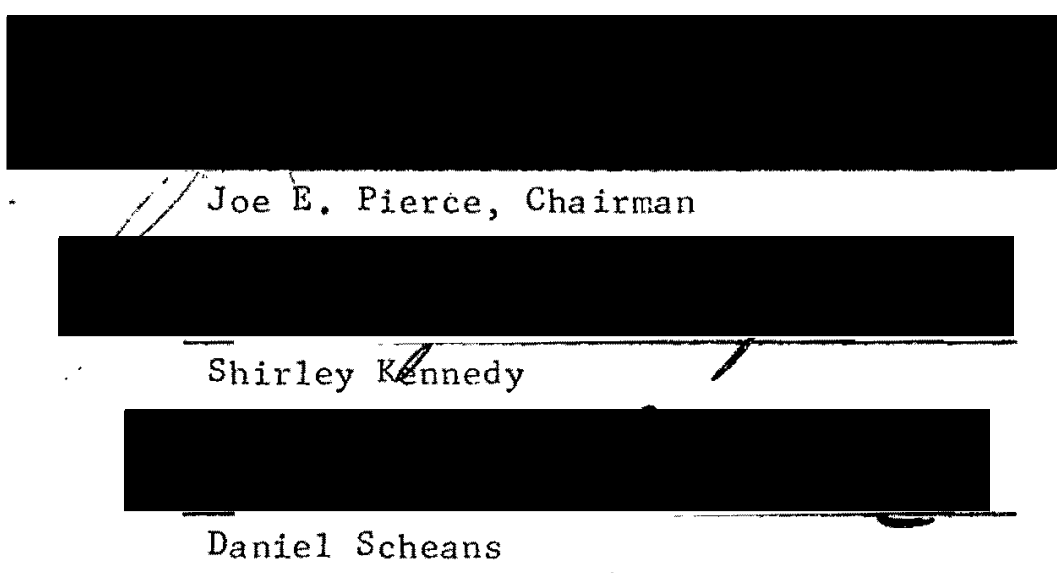

A PPRnUFn.

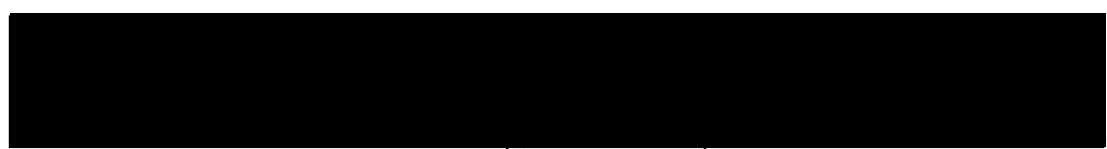

Thomas Newman, Chairman, Dept. of Anthropology

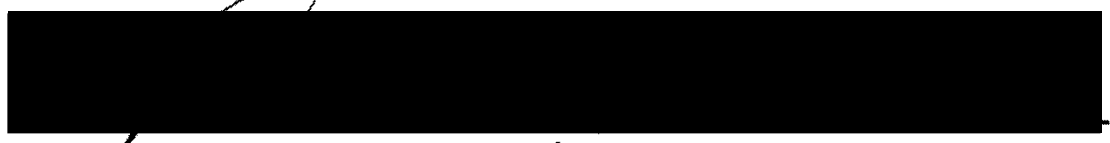

David T. Clark, Dean of Graduate Studies

Date: 


\section{ACKNOWIEDGMENTS}

I would like to offer thanks to:

Dr. Joe E. Pierce for encouraging my belief that anthropology and the "hard sciences" can work together toward common goals; Dr. Shirley Kennedy for opening my mind to cognitive anthropology; and $\mathrm{Dr}$. Jerrold Levy for helping me put it all together.

A special thanks are due to Dr. William Whetsell for pointing out to me that synaesthesia was indeed a phenomenon. 
TABLE OF CONTENTS

ACKNOWLEDGMENTS

Page

Chapter

$\mathrm{I}$

INTRODUCTION •

II

REVIEW OF IITERATURE . . . . . . . . . . 3

III

I. Definition of Terms _ . . . . 12

II. Specific Research Hypothesis . . . . . 22

III. Implications of Results . . . . . 23

IV RESEARCH METHODS * . . . . . . . . . 26

I. Subjects . . . . . . . . . . 26

II. Selection of Synaesthetics . . . . . 26

III. Determination of Class . . . . . . 27

IV. Study of Individual Synaesthetics . . . 28

V RESULTS AND OBSERVATIONS . • . . . . . . . 30

I. Class Distribution . . . . . . . 30

II. Types of Synaesthesia . . . . . . 31

III. Incidence of Mixed Dominance . . . . 33

IV. Sex Distribution . . . . . . . 33

V. Earliest Childhood Memory . . . . . 34

VI. Other Findings . . . . . . . . 34 
iii

Chapter

VI DISCUSSION OF RESULTS AND OBSERVATIONS .

I. Synaesthesia and Class

II. Possible Causative Factors in Synaesthesia

III. Types of Synaesthesia

VII $\underline{\text { Page }}$

36

36

37

41

43

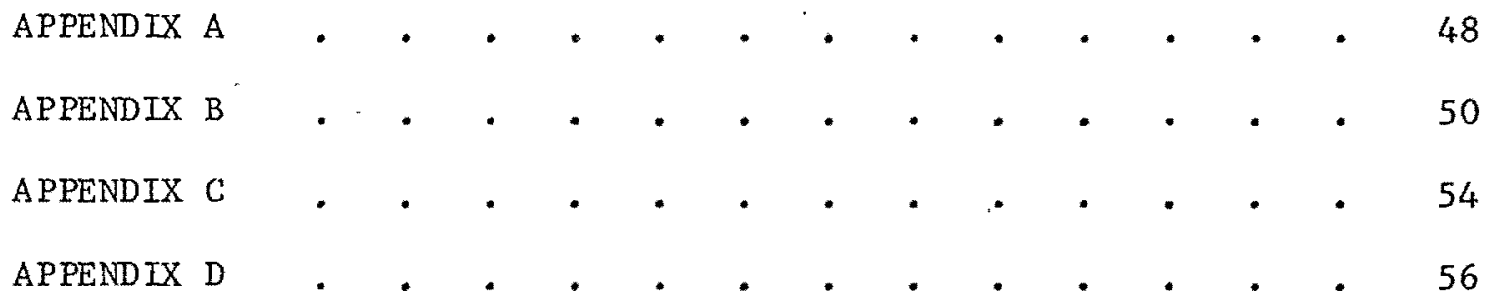


LIST OF TABLES

Tables

Page

I

Class Distribution in Synaesthetics and Non-synaes thetics. .

Chi-square Contingency Table with Numerical

Distribution of Synaesthetics and Non-

Synaesthetics According to Class . , . . . 31

III

Distribution of Synaesthesia Types . . . . . . 32

IV

Chi-square Contingency Table of Sex Distribution of Synaesthetics and Non-Synaesthetics

33

V

Age of Earliest Recollection Among Synaesthetics

34 


\section{LIST OF FIGURES}

Figures

Page

1

Illustration of the Visual Process . . . . 13

2

Classifjcation of Synaesthetic Phenomena

With Examples

15

3

Types of Synaesthesia,

Simpson and McKe11ar $(1955 ; 142)$

16 
Chapter I

INTRODUCTION

\begin{abstract}
Synaesthesia is usually defined as "a phenomenon in which a stimulus presented in one mode seems to call up imagery of another mode as rapidly as that of its own" (Simpson and McKellar 1955). For example, tones of music may be coupled in the hearer's mind with vivid colors, and will have been so coupled consistently for the whole of the subject's life. The incidence of synaesthesia is not so rare as was once thought, occurring in approximately $20-25 \%$ of the adult population (Wundram 1968-71), but why it occurs in some individuals and not others is unknown.
\end{abstract}

As a child grows from infancy to adulthood he passes through a series of stages, or levels, or cognitive development. These stages have been variously named by the investigators in this field, and are defined and discussed more thoroughly in Chapter II. However, for purposes of introduction, it can be said that after a period of sensorimotor development a child must pass through a concretistic (Piaget 1969), or syncretic (Werner 1957) stage before he is capable of symbolic (Bruner 1967), formal (Piaget 1969), or analytic (Werner 1957) thought. The German school of developmental psychology has suggested that synaesthesia is an expression of syncretic thought processes (Werner 1957), 
and, indeed, synaethesia seems to be rather common in children during the period of syncretic or concretistic development (early grade school years). However, as a child grows older, in Western societies at least, he is expected to "think" more analytically. Our education system is devoted to training children in the analytic mode of thought. In spite of this, however, a certain percentage of adults retain their synaesthetic abilities. The question is why.

Werner (1957) has proposed that synaesthesia is more common in societies which stress syncretic rather than analytic thought processes in day-to-day behavior. Ideally, this proposition could be investigated by studying the incidence of synaethesia in various cultures around the world. Less ideal but more readily available are the various subcultures within our own American society. As Marvin Harris put it, "cultural contrasts between class-linked 1 ife-style specialties are as great as contrasts between life in an Eskimo igloo and life in a pygmy village of the Ituri forest" (Harris 1971). To what extent this statement holds true for the various socio-economic classes in the United States is a question beyond the scope of this thesis. However, as a starting point and basis for future research, it is proposed herein to study the incidence of synaesthesia as it relates to class in one segment of American society: 
Chapter II

REVIEW OF LITERATURE

The phenomenon of synaesthesia was first thorough1y described by Galton (1883), and was a topic of considerable interest in those early days of scientific investigation into human psychology.

One of the earliest studies on the subject was carried out at Wellesley College in 1893 as a part of a course in experimental psychology (Calkins 1893). In this investigation it was shown that certain individuals consistently associated a certain color with each letter of the alphabet, each numera1, or each note of the musical scale. In addition, some subjects arranged in their minds the hours of the day, days of the week, months of the year, centuries of time, or even the numbers themselves into specific spatial arrangements which were unique to and consistent for each subject. The majority of individuals studied said that their synaesthesia began in childhood as far back as they could remember.

Myers (191.1) followed this study with a report on a case of synaesthesia in a young musician who always saw colors associated with the musical notes. In addition, he saw colors with the sound of human voices and the various musical instruments. The subject claimed that he had done this al1 his 1 ife. 
Langfield (1914) also described in detail a case of synaesthesia in a young woman musician and composer who had been playing the piano since age three. She was tested in 1905 and again in 1912. The colors she saw for each note of the scale were identical in the two tests, demonstrating the persistence and consistency of the phenomenon throughout the years.

It was recognized that synaethesia may occur in varying degrees and intensities in different individuals by Kerr and Pear in 1932, who state that "the use of simile or metaphor may perhaps be regarded as the entrance door to synaesthesia. At the other extreme a person's synaesthetic experiences (e.g. or color) are not only original, but may take the form of images so disturbingly intense that they may be eidetic" (1932:167). (An eidetic image is formed by certain individuals who have the capacity to project, as it were, and superimpose one visual image upon another. It seems to occur outside one's head, in the field of vision, while a synaesthetic response usually occurs inside one's head.)

Karwoski and Odbert (1938) found that $60 \%$ of a group of individuals showed some tendency to associate color with short musical selections, but only a few of these were considered to be "true" synaesthetics. A "true" synaesthetic, to these authors, was one who saw colors associated with the sounds of various tuning forks.

Perhaps the most exhaustive study of a single synaesthetic subject was done by the Russian physiologist A. R. Luria, as reported in 
The Mind of a Mnemonist (1968). The individual in this case "was so filled with synaesthetic responses that everyday commication was severely hampered, and he was able to earn a living only as an entertainer, perforning fantastic feats of meniory based on the highly: complex synaesthetic imagery in his head.

Except for this remarkable account by Luria, however, the study of synaesthesia and other forms of imagery lost its popularity during the mid-part of this century. Perhaps this lack of interest was due to a relatively greater emphasis being placed on developing theories of personality and the understanding of psychological disorder. Freudian and neo-Freudian, concepts wère in vogue, ànd "super-organicists": were stressing the powerful influence of culture on personality. However, these ideás began to pale in the light of increased knowledge about personality types: in other. cultures, and psychological growth. and development in children. The old sweeping generalizations were recognized as being too simplistic, and in the past decade there has been a return to emphasis on the individual: cognitive diversity and its organization (Wallace 1970), and the biological bases of behavior (Chapple 1970).

- With regard, to cross-cultural anthropology, the work of Bruner and others (1966) has suggested that modes of thinking, or cognitive norms, may differ considerably from one culture to the next. For example, cognitive, norms valued in some societies are predominantly. concretistic, while others, such as our western society, tend to be 
more "formal1y" oriented, to use Piaget's term (1969). Werner (1957) agrees with this concept and suggests that synaethesia, as an expression of syncretic or concretistic thought, would be more common among nonWestern peoples. An alternative to this point of view is proposed by Cole, Gay, Glick and Sharp (1971) and by. Slobin (1972) who believe that cultures may vary but cognition remains the same. These investigators would expect to find the same incidence of synaesthesia in al1 cultures.

Perhaps at this point it would be prudent to expand on some of the terms and concepts used by various theorists on human cognition. It is generally accepted that one's cultural upbringing does, to a certain extent, affect one's perception of the surrounding world. For example, a Turk cannot hear the difference between "bit" and beet", but this is because his learned (language) categories are constructed quite differently, neurologically, from those of an English-speaker. This does not imply that his cognition differs from that of an Englishspeaker. It is quite plausible that a Turkish child learns his language in much the same manner that an English child learns his, and that an adult college-educated Turk uses his language in much the same manner and for the same purposes that an adult college-educated Englishman does. Whether or not this plausibility is indeed a fact is not known. But perception (of phonemes, for example) is not the same as cognition.

"Perception" could be defined as the act of being aware of certain stimuli, selected from the vast range of stimuli which constantly bombard us from the environment. Which stimuli are selected for perceiving is 
to a greât extent culturally determined. What one does with these perceived stimuli is "cognition", and it is this next level of mental activity that cognitive anthropologists are interested in studying.

One of the ways in which cognition is studied is from a developmental point of view. As mentioned previously, Piaget, Bruner, Werner (and many other psychologists not cited) seem to agree that the growing child passes from a sensori-motor period of development, through a concretistic or syncretic stage, before finally entering the period of adult, or symbolic, thought processes. In the sensori-motor stage, the child's brain is occupied with learning basic fundamental facts about the environment. As the child begins to learn language and other information pertinent to his culture, he moves into the next stage of development.

According to Piaget, the pre-school child uses preconcepts, or representations (i.e., stimuli to represent other objects) that are midway between the concept of an object (this table) and that of a class (all tables). This type of cognition is termed "concretistic" ("syncretic" by Werner). Aithough Piaget himself does not discuss the phenomenon of synaesthesia per se, other psychologists have considered synaesthesia to be a natural outcome of this form of cognition. "A lack of differentiation in conceptualizations sometimes extends to the point of fusing the data from the various sense modalities. Although by no means present in all children, so-called synaesthesia occurs when a specific stimulus arouses not only the corresponding sensation 
$y$

but also another sense-modality united with it... This phenomenon tends to disappear with increasing age, suggesting that it is related to increasing differentiation" (Watson 1965:315).

These findings of Piaget and others have raised questions among anthropologists:

- Do children of all cultures pass through these stages?

- Are people of "primitive" (i.e., non-Western) cultures more concretistic (and therefore more "childlike") in their cognitive processes than those of Western cultures?

It seems beyond the limits of the present investigation to present an exhaustive review of the literature on these questions, although considerable work has already begun in this area. With regard to the thesis at hand, however, it should be mentioned that Heinz Werner was one of the first to use anthropological data to support his theory of cognitive development. Werner has been criticized on many counts, not the least being his apparent assumption that "primitive" adults are cognitively similar to "civilized" children. However, as Cole, et al., have pointed out, "his position was not intended to be a strong claim about either genetic endowment or possibilities for developmental change. His major goal was to provide a general structural paralle1 (not material identity) between child and primitive, which would allow one to seek and order information about other societies in terms that coordinate with an organization of knowledge about individuals within 
our own society" (1971:16). The conclusions of these investigators based on their own research is that "cultural difference in cognition resides more in the situations to which particular cognitive processes are applied than in the existence of a process in one cultural group and its absence in another" (Cole, Gay, Glick and Sharp 1971:233).

However, Werner's proposition runs counter to this, for he states that while for the Western ("civilized") adult synaesthesia is a syncretic thought process outgrown in childhood, for the non-Western ("primitive") adult who is very syncretic in his thought processes synaesthesia would be a common occurrence.

In spite of the rising tide of interest in human cognitive processes, synaesthesia itself, as a topic for research, has still not received the attention it did in previous times. However, there has been a rekindled interest in imagery in general (Horowitz 1970; Paivio 1971), and synaesthesia is generally considered to be a form of imagery... Perhaps the most thorough investigation in recent years has been conducted by Simpson and McKellar (1955), who attempt to classify the various types of synaesthesia they observed. They group their findings into two broad categories: 'nätural and experimental, noting that synaesthesia can be experimentally produced, for example, with mescaline, and may continue for a time in individuals not ordinarily synaesthetic. However, they state that "synaesthèsias of any kind are by no means common, and those ordinarily reported tend strongly to be of the visual-auditory type" $(1955: 142)$. 
Although this belief may be the underlying basis for the dearth of research in the area, it is ill-founded. Not only is synaesthesia quite common among children, it is by no means a rarity among adults. The following statistics are quoted by Werner (1957:90-91):

According to the majority of investigators this special field of sensory experience is quite frequent in children.

Révész, reviewing the earlier literature on synaesthesia, finds "color-hearing to be very common among children. Children often associate tones, words, noises, etc., with color of a certain value." He quotes Stanley Ha11, who estimated that approximately 40 per cent of the pupils of a small school described the tones of various instruments in terms of color. Lemaitre speaks of this as a widespread occurrence. Bleuler and Schumann discovered that many of their experimental subjects had been aware of photism since early youth. Some could even tell fairly accurately just when they first noted it, most of them judging it to be somewhere between the ages of six and eight years. A more methodical investigation carried out by Révész in the Montessori School in Amsterdam tends to corroborate Hall's statement. Approximately half of the twenty children in the school definitely showed signs of chromatism. Révész was astonished to find that al1 the children readily answered the questions about color-numbers presented to them, regardless of whether in reality they were particularly gifted with the capacity for synoptic sensory experience.

The question as to whether this chromatism tends to diminish in the course of individual development has never been satisfactorily answered. We do know, at least, that tonal color, in its common form is much more frequently ascribed to children than to adults. Bleuler and Lehmann found only 12.7 per cent of 596 adults to be gifted with chromatism; Calkins in a similar investigation set the ratio at 15.7 per cent. Chromatism as found in children and adults is in the proportion 50/14.2 according to these reports. Argelander in her survey points out that photism is often known reminiscently by the adult subject; some adults declare that they noticed their photism during their youth but that it slipped out of their mind. Révész compared the behavior of younger children with that of a group of school children who were all eleven years of age, and also with that of another group of ten children seventeen years old, in order to determine the relative frequency of chromatic experience; he came to the conclusion that there is a distinct 
regression of the faculty from the eleventh year onward. With eleven-year-olds the ratio of those having the gift of perceiving color-tone to those not so gifted ranges from 25-30 per cent.

The foregoing survey of the 1iterature reveals that synaesthesia is still a poorly understood phenomenon. It has not even been properly defined, and each investigator seems to be pursuing a different aspect of the matter in many cases, rendering impossible any meaningful comparison of their separate efforts. In the following section, a rational definition of synaesthesia will be presented with further examples from the literature in an attempt to place the works of others as well as from the work herein described, in a comprehensible perspective. 
Chapter III

\section{DESCRIPTION OF THE PROBLEM}

\section{DEFINITION OF TERMS}

As stated in the previous section, a precise definition of what is meant by synaesthesia is clearly needed. The confusion comes in when no clear distinction is made between the stimulus and the synaesthetic response. For purposes of the present investigation, stimuli capable of evoking such a response will be classified as either sensory or symbolic; similarly, the responses themselves can be grouped as either sensory or symbolic.

These terms can be defined and the neurological events illustrated by considering a single modality: the visual process. The retina of the eye is a specialized sensory epithelium constructed to respond to that tiny portion of the electromagnetic spectrum between 400 and 700 millimicrons in wavelength. We call this the "visible" spectrum. The retina is capable of projecting these stimuli onto the primary visual cortex, a discrete portion of the occipital lobe of the brain, called area 17. At this level one may be "consciously" aware of the stimuli which excite the retina, but before these stimuli can have meaning or be identified (have "names" or be categorized), they must be relayed to the adjacent visual-associative cortex: areas 18 and 19 
(Peele 1961; Crosby, et a1. 1962)。Area 17 is sensory cortex;

areas 18 and 19 are symbolic cortex.

This concept is further illustrated in Figure 1. Light strikes an object, in this case an apple, which reflects onto the retina. The retina projects the entire image, as it were, onto the primary visual cortex. In the norma 1 human adult, the stimulus is immediately relayed to the adjacent visual-associative area for categorization and identification. Three such categories for an English-speaker might be "red", "round", and "apple". One who is injured in these associative areas will see the apple just the same, but may be unable to name it or describe it. He will, however, be able to paint a picture of the apple just as he saw it. If his injury is in the primary visual cortex instead, he will not be able to see the apple at all. In the former case he has "visual agnosia"; in the latter he is "cortical1y blind" (Luria 1966).

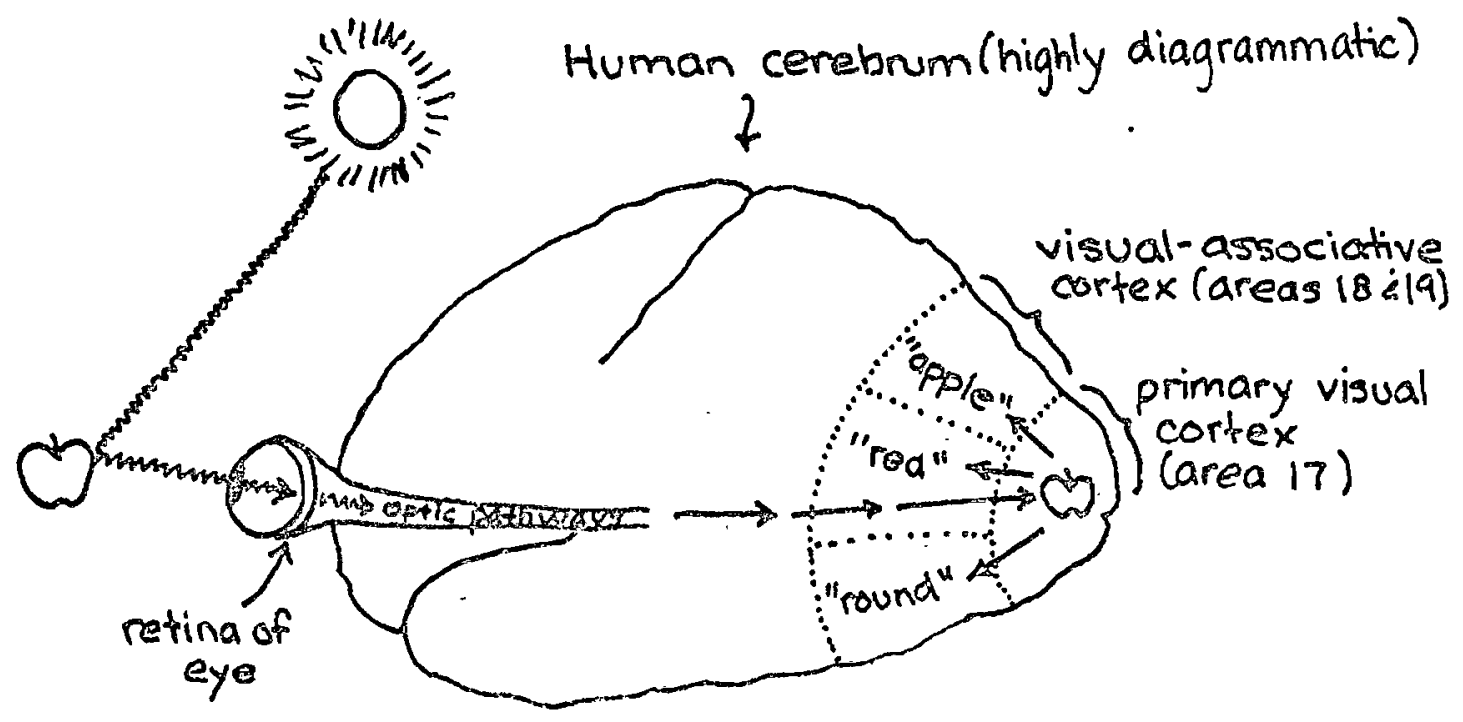

Figure 1. Illustration of the visual process. For explanation, see text. 
From the visual associative cortex, stimuli are projected to the other associative areas of the brain, where more elaborate symbolic activities take place.

The foregoing explanation has been presented in an attempt to distinguish between the terms "sensory" and "symbolic". A sensory event in the brain occurs in a primary sensory cortex, be it visual, tactile, auditory, or whatever. A symbolic event occurs in the secondary or associative areas of the cortex. In the visual sequence of events, the sensory cortex projects onto the symbolic cortex and our awareness is usually focussed at the symbolic level (Ornstein 1972). Thus, when we "see" the object in Figure 1, we immediately think "apple". In this case the excitation in the sensory cortex is a stimulus projecting onto the symbolic cortex, and our awareness is the response.

In synaesthesia, this sequence of events is altered. Although the precise neurological mechanisms involved have never been described, it is as though awareness is focussed at two primary sensory cortex areas simultaneously, or, in another type of synaesthesia, awareness may be focussed on a certain portion of a sensory cortex at the same time that a symbolic cortical event is taking place.

It is important for the sake of clarity to maintain a distinction between the "stimulus" event and the "response" event. Throughout the literature this distinction is not always made, and the term "synaesthesia" has been applied to refer to one or several of four 
discrete but related phenomena. These phenomena are summarized. briefly in the following chart:

\begin{tabular}{|c|c|c|c|c|}
\hline \multicolumn{3}{|c|}{ SYNAESTHETIC PHENOMENON } & \multicolumn{2}{|c|}{ EXAMPLE } \\
\hline & STIMULUS: & RESPONSE: & STIMULUS: & RES PONSE: \\
\hline 1 . & sensory & - sensory & $\begin{array}{c}\text { musical tone } \\
(512 \mathrm{cycles} / \mathrm{sec})\end{array}$ & $\begin{array}{l}\text { color } \\
\text { (602 rus) }\end{array}$ \\
\hline 2 . & symbolic & - sensory & $\begin{array}{l}\text { letters of } \\
\text { alphabet (E) }\end{array}$ & $\begin{array}{l}\text { color } \\
(467 \text { imu })\end{array}$ \\
\hline 3 . & sensory & - symbolic & $\begin{array}{l}\text { color } \\
(591 \mathrm{mu})\end{array}$ & $\begin{array}{l}\text { ideas of emotions } \\
\text { ("anger") }\end{array}$ \\
\hline & symbolic & - symbolic & $\begin{array}{l}\text { words } \\
\text { ("free as } \\
\text { ("cat") }\end{array}$ & $\begin{array}{c}\text { words } \\
\text { ("dogtion) }\end{array}$ \\
\hline
\end{tabular}

Figure 2. Classification of synaesthetic phenomena with examples.

Each of these will be described more thoroughly below.

\section{Sensory-sensory}

This is perhaps the "pure" or "true" synaesthesia that authors refer to when they describe the association of one sensory modality with another, for example, the experiencing of colors of precise wavelengths with the sounds of various tuning forks (Langfield 1914). Simpson and McKellar described this form of synaesthesia only, and report their findings in the following chart. (1955:142): 


\begin{tabular}{|c|c|c|c|c|c|c|c|c|}
\hline \multirow{2}{*}{$\begin{array}{l}\text { Imagery } \\
\text { Experience: }\end{array}$} & \multicolumn{8}{|c|}{ Sensory Experience: } \\
\hline & visual & audit & tactile & gustat & olfact & kinaesth & therm & algaes \\
\hline visual & - & NE & NE & $\mathrm{N}$ & $E$ & $\mathrm{E}$ & $E$ & $E$ \\
\hline auditory & & $-\infty$ & & & & & & \\
\hline tactile & $N E$ & $\mathrm{NE}$ & -- & & $E$ & & & \\
\hline gustatory & ' & & & -- & & . & & \\
\hline olfactory & & & & & -- & & & \\
\hline kinaesthetic & & & & & $N$ & - & & \\
\hline therma 1 & $E$ & & & & & & -- & \\
\hline algaesic & & $\mathrm{E}$. & & & . & & & -- \\
\hline
\end{tabular}

Figure 3. Types of synaesthesia, Simpson and McKellar (1955:142).

Neurologically speaking; it is as though the stimulus occurs in one primary sensory cortex and the response occurs in another.

In the example given in Figure 2, the auditory cortex is excited by vibrations of a certain tuning-fork of, say, 512 cycles per second. This sensation is consistently linked with a response in the visual cortex which corresponds to that which occurs when it is excited by a precise wavelength of 1 ight, in this case 602 millimicrons. The individual may then use words to describe his experience, but the event itself is non-verbal, or pre-verbal. It is a sensory-sensory synaesthetic experience. 
It is possible that this type of association is directly physiological, similar to "referred" pain, where a sensation in one part of the body (e.g., the intestine) is referred to some other part (e.g., the left shoulder). Schilder sums it up as follows:

"We no longer believe that there are isolated senses. Impression of the tactile and auditory spheres are always connected with optic impressions; synaesthesia is not an exceptional occurrence but is one of the basic principles of perception" (1942:84). The fact remains, however, in day-to-day functioning, not everyone is atvare of or dependent upon such association of two or more senses, as is the synaesthetic.

\section{Symbolic-sensory}

In this type of synaesthesia, the subject associates a primary sense, such as color, spatial arrangement, tactile qualities, smell, or taste, with some sort of verbal or symbolic stimulus, such as a word, the letters of the alphabet, music (as opposed to pure tones), numbers, days of the week, and so on. This is the type of synaesthesia described by Calkins (1893). It is as though the individual uses the primary senses as a sort of mental crutch for handing basic symbolic data. Luria's subject expresses it as follows: "For me to come up with the right word at the right time, I have to fit all these forms and colors together. On the one hand, it makes for complications, but on the other, it is a way of remembering words" (Luria 1968:90). Further on he says, "Even when I 1isten to works of music, I feel the taste of them on my tongue; if I can't, I don't understand the music. 
This means I have to experience not oniy abstract ideas, but even music, through a physical sense of taste" (1968:134). (In this instance, however, the music he is trying to understand is also an abstract idea.)

Again, using our neurological model, we can describe this type of synaesthesia as a stimulusmevent in the symbolic or associative areas of the brain coupled with a response-event in one of the primary sensory cortex areas. In Figure 2, the example was the letter E (a common symbol for users of the Roman alphabet) being linked consistently with a color of a precise wavelength, here, 467 millinicrons.

\section{Sensory-symbolic}

This type of association is distinguished from the former by the fact a sensory modality is the stimulus which conjures up abstract thoughts and ideas, rather than the reverse. An example would be a precise wavelength of light being associated with danger or passion. Pecjak's (1970) investigation showed that there was a strong correlation in his subjects between colors and certain emotions. This phenomenon is quite wel1-known, and often made use of by artists and composers. For instance, Tschaikovsky in his Peter and the Wolf uses the tones of the various musical instruments to represent the personalities of different characters in the story.

It is important to note that the stimulus-event here must be truly sensory (arising in one of the primary cortex areas). It is possible that, instead of a precise wavelength of light, a category of wavelengths, such as our own English symbol "red", could also 
produce a response of "danger" or "passion". In this case the synaesthetic event would not be sensory-symbolic, but would be classed in the category below.

\section{Symbolic-symbolic}

This is the familiar word-association phenomenon used by psychoanalysts and laymen alike. Here, the subject is asked to say whatever word comes to mind when a certain other word is heard. Entwisle (1966), for example, has studied word-association for a long 1 ist of common English words as made by a large number of individuals ranging in agegroups from kindergarten to adulthood.

It is questionable whether the latter two phenomena, sensorysymbolic and symbolic-symbolic, should be classed as synaesthetic. According to our neurological definition, both occur almost universally among norma 1 human adults and could be considered as aspects of everyday thought-processes, at least in Western cultures. However, the other two types, symbolic-sensory and sensory-sensory, do not occur universa11y. Only a certain percentage of the adult population experience these phenomena. The question is why.

Sensory-sensory synaesthesia is probably quite rare, and may indeed be a neurophysiological quirk peculiar to certain individuals, similar to referred pain, as mentioned before. However, the line between sensory-sensory and symbolic-sensory is not quite clear at our present level of knowledge, especially where music is concerned. A symbolicsensory synaesthetic links.colors with music as a stimulus with symbolic 
meaning, while a sensory-sensory synaesthetic links colors with the sound, or pure tones. of the music, divorced from any meaning the music may have. Because these two types of syneesthesia are perhaps closely related, they will both be considered for study in the investigation to be described below, while the other two forms (sensory-symbolic and symbolic-symbolic) will not be studied, since, as they are defined in this section, they are not truly synaestiesias.

Further criteria for true synaesthesia, based on previous studies (Ga1ton 1883; Calkins 1893; Langfield 1914; Wundram 1968-71) are:

1. the response is always the same for the subject (A is always a color of a specific wavelength);

2. the response has been present as long as the subject can remember.

The discussion of synaesthesia from a neurological point of view not only serves to clarify the distinction between sensory and symbolic mental events, but also suggests that the occurrence of synaesthesia is neurologically determined, i.e., the brain of the synaesthetic is structurally different from the brain of the non-syraesthetic. This is not to say that cultural determinants are not involved, for it is an individual's cultural training which "prograns" the categories in the association areas of the cortex. However, it is possible that there is some structural difference in the brain of a synaesthetic which prevents him from growing out of his natural childhood synaesthesia. 
Preliminary investigations have suggested that synaesthesia may be associated with incomplete dominance in the two hemispheres of the cerebrum (Wundram 1968-71). In the majority of individuals, the left hemisphere (controlling the right side of the body) is dominant.

The left hemisphere . . . is predominantly involved with analytic, logical thinking, especially in verbal and mathematical functions. Its mode of operation is primarily linear. This hemisphere seems to process information sequentially. This mode of operation of necessity must underlie logic 1 thought, since logic depends on sequence and order. Language and mathematics, both left-hemisphere activities, also depend predominantly on linear time.

If the left hemisphere is specialized for analysis, the right hemisphere (. . .. connected to the left side of the body) seems specialized for holistic mentation. This hemisphere is primarily responsible for oux orientation in space, artistic endeavor; crafts, body. image, recognition of faces. It processes information more diffusely than" does the left hemisphere, and its responsibilities demand a ready integration of many inputs at once.

This right-left specialization is based on right-handers. Lefthanders, who are about 5 per cent of the population, are less consistent; some have reversed specialization of the hemispheres, but some have, mixed specialization--e.g., language in both sides. Some are specialized in the same way as righthanders. And even in righthanders these differences are not binary, but are specializations of each "half-brain:" At least in very young people, each" side does possess the potential for both modes; e.g., brain damage to the left hemisphere in young children often results in the development of language in the right side.

(Ornstein 1972:51-52):

It should also be noted that many investigators are of the opinion that different cultures encourage the development of one hemisphere's activities over the activities of the other (Bruner 1965; Lee 1950; 
Ornstein 1972). This is not the same as saying non-Western cultures are more concretistic and therefore more "childlike" than Western cultures. On the contrary, this theory assumes that there are two modes of thinking possible for human beings and one's culture determines which mode will become the dominant one in adult life. Whether or not children from both culture-types develop in the same manner, however, is still a central question. In addition, the relationship of hemispheric dominarce to the occurrence of synaethesia is a matter to be further pursued.

\section{SPECIFIC RESEARCH HYPOTHESIS}

In previous sections it was mentioned that the German school of developmental psychology (Werner 1957) has proposed that synaesthesia would be more common in societies which stress syncretic rather than a nalytic thought processes in everyday behavior. It was also suggested that an ideal approach to this problem would be to investigate the occurrence of synaesthesia among peoples from many varying cultures around the world. At the present level of investigation, such an ideal research situation is not possible, nor is it necessarily advisable, considering the lack of information available on synaesthesia itself. A more feasible approach would be to study the incidence and nature of synaethesia within a single culture, relating its occurrence to a controlled set of variables within that culture, such as socio-economic class. Future research could include a study of more divergent subcultural groups within the society, slich as American Indians and 
ghetto blacks. The research described herein serves as a starting point for such future investigations.

In other words, the specific hypothesis to be tested here is that the occurrence of synaesthesia is class dependent.

This hypothesis will be tested by conducting a survey of high school students from the Portland area. The survey will provide the following information:

1. relative incidence of synaesthesia among high school students;

2. distribution of socio-economic class among synaesthetics and non-synaesthetics;

3. additional information on the nature and varieties of synaesthesia, including its relationship to hemispheric dominance.

III. TMPLICATIONS OF RESULTS

1. If synaesthesia is found to be equally (randomly) distributed in all socio-economic classes, we might assume that income, parent's education, and class-identification are not major factors involved in the phenomenon. It is possible that some other cause, such as incomplete cerebra1 dominance and related neurological patterns could be operative here. If synaesthesia is indeed an index of syncretic thought, as Werner has suggested, then the education system is successful in its goal to train childran of all economic backgrounds in the analytic mode of thought. However, the finding that synaesthesia 
is not class-dependent does not necessarily mean it is not culturallydependent. Cultural differences greater than socio-economic class might conceivably be related to the occurrence of synaesthesia, and would have to be investigated in another study.

2. If synaesthesia is found to be more frequent among children from low-income families, this would suggest that children of lower class families actually think differently from children of middleclass families. This does not necessarily mean that the lower socioeconomic classes in America are more syncretic than analytic, but such a finding would be relevant to a cross-cultural investigation of Werner's hypothesis. For example, if synaesthesia were found to be very common in both "primitive" cultures and lower economic classes in "civilized" cultures, the possibility would have to be explored that the two groups share some common cognitive trait.

3. If, on the other hand, synaesthesia is more predominant among the upper-income students, the suggestion could be made again that these people think differently from their lower-income fellow students. In this case, synaesthesia might be retained in children of educated, creative parents who encourage syncretic thought for its own value. Cross-cultural studies would still have to be carried out to supplement this finding, before any statement could be made regarding the cultural etiology of synaesthesia.

In brief, the nu11 hypothesis here is that synaesthesia is not class-dependent. If this hypothesis is borne out by experimental data, 
further research will be required to determine what variables are important in the occurrence of this phenomenon. Similarly, if the data indicate that synaesthesia is indeed class-dependent, further research will still be needed to determine to what degree synaesthesia is culture-dependent, and what implications these findings could have for cognitive anthropology. 
Chapter IV

RESEARCH METHODS

\section{SUBJECTS}

Students of Andrew Jackson High School, Portland, Oregon, were chosen as subjects for this study. Their ages ranged from 15 to 18 years, for at this age-level, the individual's analytic abilities should be fully developed (Piaget 1969; Bruner 1967). High school students were preferred over college students as subjects because the latter, through their own initiative or that of their parents, have shown their preference for the analytic mode of thought by choosing to continue their education.

\section{SELECTION OF SYNAESTHETICS}

The students were initially gathered in large groups for the purpose of administering a questionnaire to separate the synaesthetics from the non-synaesthetics. The questionnaire (Appendix A) was carefully explained and the students were requested to write their synaesthetic responses, if any, on a blank sheet of paper attached to the questionnaire. The questioning procedure was informal but standardized (Appendix B), and sought to uncover synaesthetic tendencies in the subjects according to the following criteria: 
1. the response is always the same for the individual;

2. the response has been present as long as the subject can remember.

Because of the difficulties inherent in communicating with so many persons in a large group, only the more common forms of synaesthesia (Wundram 1968-71) were sought. These were mostly symbolicsensory, with a single example of sensoryusensory. To be exact, the students were asked if they experienced colors, spatial arrangements, sme11s, or tastes; or any other sensations with any of the following:

- letters of the alphabet

- days of the week

- months of the year.

- centuries or years of time

- the numerals

- notes of the musical scale (the only sensory-sensory

- example)

- any other music

The subjects were encouraged to consider not only the above but a1so any related phenomena in themselves as we11.

\section{DETERMINATION OF CIASS}

The socio-economic class rating of each student was determined using Hollingshead's Two-Factor Index of Social Position (Hollingshead 1957). In this index, a persons rating is determined by his occupation and education (in the present case, the student's father, or the head-of-household). A numerical value is assigned to the various levels 
of occupational and educational attainment and multiplied by a constant to give a score which is an index of social position. These scores are grouped into classes I, II, III, IV, V, with I being the highest and $\checkmark$ the 1owest. (See Appendix D.)

\section{STUDY OF INDIVIDUAL SYNAESTHETICS}

Those subjects whose questionnaires showed that they had definite synaesthetic tendencies were called in for a second, individual interview (Appendix C). Although brief, this interview allowed the subject to elaborate on his particular synaesthetic response, and provided further information on family background and outside interests of the subject.

To determine the possible relationship between synaesthesia and incomplete dominance of the brain, the subject was asked if he was right- or left-handed and right- or left-footed, and was tested for dominant eyedness in the following manner: The subject was asked to hold a paper tube at arm's length and to focus on a distant object with both eyes looking through the tube. He was then asked to close first one eye then the other, and to report which eye he was actually using to look through the tube. This was recorded as the dominant eye (Luria 1966:321-323).

This second interview also served to weed out the "false positives", i.e., those who responded to the first questionnaire in a manner similar to true synaesthetics, but who were in fact non-synaesthetic. This was 
usual1y determined by discovering through careful questioning that the response was variable, or forced, or was not a part of the subject's cognitive processes. The students were quite willing to elaborate on their initial responses to the point that there was no doubt as to who was synaesthetic and who was not. 


\section{Chapter V}

\section{RESULTS AND OBSERVATIONS}

Out of 82 subjects interviewed in the initial survey, 41 were found to be synaesthetic to some degree, an incidence of $50 \%$.

\section{CLASS DISTRIBUTION}

The socio-economic class breakdown in the two groups was as. follows:

Table I

Class Distribution in Synaesthetics and Non-Synaesthetics

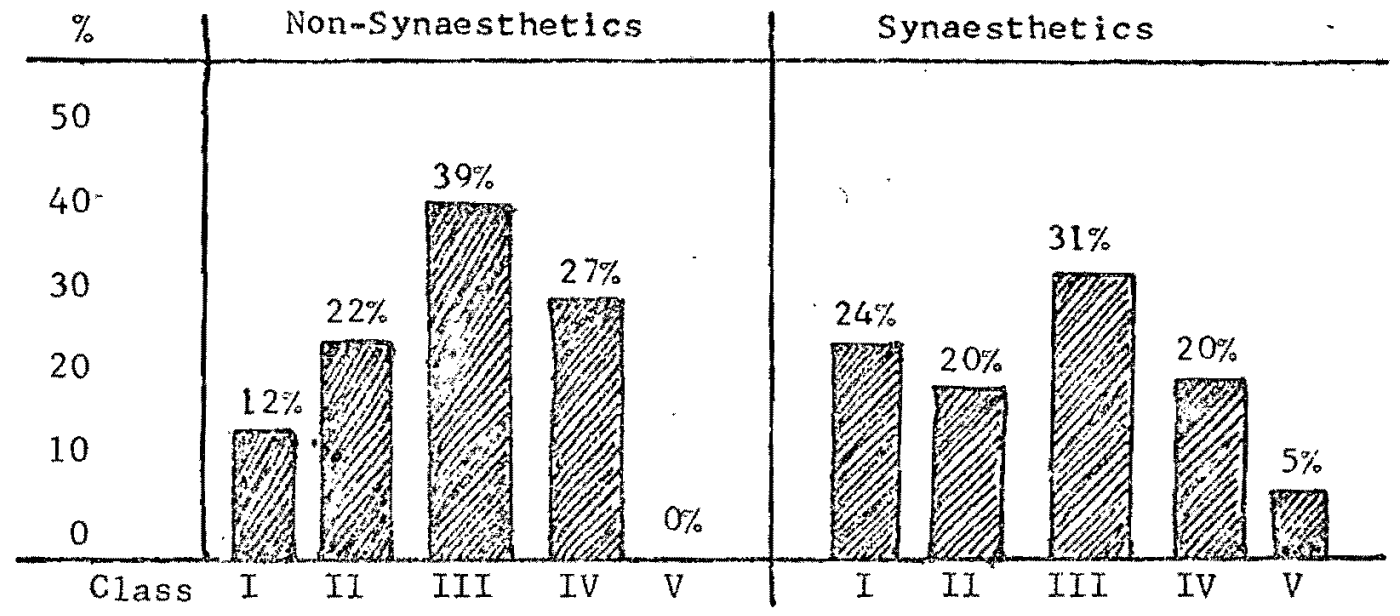

Note: These classes I through $V$ indicate socio-economic position, with class I being the highest class, and class $V$ being the lowest (Hollingshead 1957). Thus $12 \%$ of the non-synaesthetics were in class I, whereas $24 \%$ of the synaesthetics were in this class. 
A chi-square contingency table was used to determine whether the occurrence of synaesthesia was, in this sample, dependent on socio-economic class:

\section{Table II}

Chi-square Contingency Table with Numerical. Distribution of Synaesthetics and Nonsynaesthetics According. to Class

\begin{tabular}{l|c|c|c} 
Class & Non-Synaesthetics & Synaes thetics & Tota 1 \\
\hline I & 5 & 10 & 15 \\
II & 9 & 8 & 17 \\
III & 16 & 13 & 29 \\
IV \& V & 11 & 10 & 21 \\
\hline Totals & 41 & 41 & 82
\end{tabular}

$$
\begin{aligned}
& \alpha=.01 ; \text { degrees of freedom }=3 ; \cdot .70>p>.50 \\
& x_{\text {table }}^{2}=11.34 ; \quad \mathrm{x}_{\text {calc. }}^{2}=2.12
\end{aligned}
$$

The results of this statistic suggest that the occurrence of synaesthesia in this sample is not dependent on socio-econonic class.

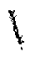

\section{TYPES OF SYNAESTHESIA}

of the 82 subjects tested, not one reported sensory-sensory synaesthesia (colors with pure musical tones, in this survey). The distribution of the various types of symbolic-sensory synaesthesia surveyed for is given in the table below: 
Table III

Distribution of Synaesthesia Types ${ }^{1}$

$\begin{array}{crcl}\text { Type of } & \text { Number of } & \text { Per Cent of } & \text { Per Cent of } \\ \text { Synaesthesia } & \text { Subjects Synaesthetics } & \text { Total Sample }\end{array}$

\begin{tabular}{lccc}
\hline Color-music & 2 & 4.9 & 2.5 \\
Color-1etters & 9 & 22.0 & 11.0 \\
Color-days & 10 & 24.0 & 12.0 \\
Color-months & 8 & 19.5 & 10.0 \\
Color-years & 2 & 4.9 & 2.5 \\
Color-numbers & 11 & 27.0 & 13.5 \\
\hline
\end{tabular}

Tota1 subjects

with chromaesthesia ${ }^{2}$

21

50.0

25.0

\begin{tabular}{lccc}
\hline Spatial-1etters & 4 & 9.8 & 4.9 \\
Spatial-days & 22 & 53.0 & 26.5 \\
Spatial-months & 11 & 27.0 & 13.5 \\
Spatial-years & 7 & 17.0 & 8.5 \\
Spatial-numbers & 7 & 17.0 & 8.5 \\
\hline $\begin{array}{l}\text { Total subjects } \\
\text { with spatiaesthesia }\end{array}$ & 31 & 75.6 & 37.8 \\
\hline
\end{tabular}

${ }^{1}$ Some subjects exhibited more than one type of synaesthesia.

${ }^{2}$ Chromaesthesia is the experiencing of colors with another stimulus.

${ }^{3}$ Spatiaesthesia is the experiencing of spatial arrangements of other stimuli. 


\section{INCIDENCE- OF MIXED DOMINANCE}

Thirty-three students returned for the second interview. Of these, twenty showed evidence of mixed dominance. Two of the students with mixed dominance were labeled as non-synaesthetic ("false-positives") after this second interview. Thus 20 out of 31 synaesthetics seemed to have incomplete cerebral dominance, an incidence of about $65 \%$.

\section{SEX DISTRIBUTION}

The distribution of sex in the two groups is reported in the following table:

Table IV.

Chi-square Contingency Table of

Sex Distribution of Synaesthetics and Non-synaesthetics

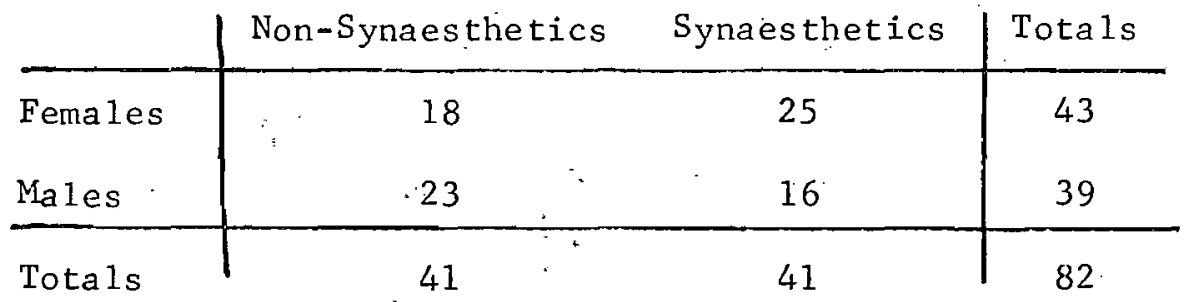

$$
\begin{aligned}
& \alpha=.01 ; \text { degrees of freedom }=1 ; .20>\mathrm{p}>.10 \\
& \mathrm{x}_{\text {table }}^{2}=6.64 ; \mathrm{x}_{\text {calc. }}^{2}=2.40
\end{aligned}
$$

The results of this statistic suggest that in this sample the occurrence of synaesthesia is not dependent on sex. 


\section{EARLIEST CHILDHOOD MEMORY}

Of the ones who returned for the second interview, the following ages were given for their earliest recollection:

$\begin{array}{cc}\text { Table V } \\ \begin{array}{c}\text { Age of Earliest Recollection } \\ \text { Among Synaesthetics }\end{array} \\ \begin{array}{cc}\text { Age of Earliest } \\ \text { Recollection } \\ \text { infancy }\end{array} & \begin{array}{c}\text { Number of } \\ \text { Synaesthetics }\end{array} \\ 1 \text { yr. } & 1 \\ 2 \text { yrs. } & 2 \\ 3 \text { yrs. } & 13 \\ 4 \text { yrs. } & 4 \\ 5 \text { yrs. } & 3 \\ 6 \text { yrs: } & 1 \\ 7 \text { yrs. } & 2 \\ & \end{array}$

None of the subjects reported a remarkably early age for learning symbolic data, such as the alphabet, or telling time. Most assumed that they had learned such things upon starting to school.

There seemed to be no correlation between number of siblings or sibling order and the occurrence of synaesthesia. 
With regard to apparent location of the synaesthetic image, most of the chromaesthetic responses occurred inside the head, while a considerable number of spatiaesthetic responses seemed to occur outside the body, usually in front within reach of the hands.

None of the subjects could conceive of the stimulus in any way other than synaesthetically, and each had had the response as long as he could remember. 


\author{
Chapter VI \\ DISCUSSION OF RESULTS AND OBSERVATIONS
}

I. SYNAESTHESIA AND CLASS

The results of this investigation indicate that the occurrence of synaesthesia is independent of socio-economic background in an individual. Within the group tested, synaesthesia was found to be equal1y (random1y) distributed among all socio-economic classes. However, there are several qualifying statements which must be added to this general conclusion. First of all, the number of subjects from the lowest socio-economic class in this sample was quite sma11, for the high school served a predominantly middle-class community. An additional survey contrasting a predominantly lower class with a predominantly upper class group would supplement these findings.

Secondly, it could be argued that any child who had attended an American public high school would be adequately trained in the analytic mode of thought, regardless of family background, and that syncretic thought does not predominate in any American subculture. However, the results herein indicate that approximately half the students of the high school studied still evidenced some degree of syncretic thought behavior well into their teens: 
A third consideration to be mentioned is that a cross-class survey is not an adequate substicute for a cross-cultural survey. In order to test Werner's hypothesis that synaesthesia is more common among non-Western peoples, this investigation could be extended to American Indian high schools, Mexican village teen-agers, and adolescents in other non-Western cultures. A cross-class study was used in this investigation because of the lack of availability of other nonWestern cultures.

II. POSSIBLE CAUSATIVE FACTORS IN SYNAESTHESIA

If synaesthesia is in fact an index of syncretic thought, but is not dependent on socio-economic background, what causes it? Synaesthesia is quite common in childhood during the period of concretistic or syncretic development (Revesz 1923; Werner 1957), but drops to an incidence of about $15 \%$ in adults (Ca1kins 1893; Werner 1957). (The results of the present study indicate that some form of synaesthesia is found in $50 \%$ of young adults. This apparent discrepancy with the literature is discussed below in Section III.) Why do some individuals retain this ability while others lose it?

Piaget and Inhelder (1971) suggest that imagery of al1 forms arises out of a need to concretize the abstractions of language. They go on to state that ". . . the image is an indjspensable auxillary in the functioning of the very dynamism of thought, but only as long as it remains consistently subordinate to such operational dynamism, which 
it cannot replace, and which it can only express symbolically with degrees of distortion or fidelity varying according to circumstances" $(1971: 390)$.

The results herein suggest that in true synaesthetics the image is an indispensable and inseparable part of the dynamism of thought, not merely an auxillary. These individuals function on a symbolic, analytic, or formal level using concretistic or syncretic thought mechanisms.

Piaget (1969) offers a further clue in his discussion of egocentrism as an obstacle to the development of logical thought. A young child can see only his own viewpoint. "He believes that everyone thinks the way he does, and that everyone thinks the same things he does. As a result, the child never questions his own thoughts because they are, as far as he is concerned, the only thoughts possible and consequently must be correct" (Wadsworth 1971:71). This is a rather exact description of a synaesthetic's opinion of his own response. It is as though his childhood associations were never questioned and became fixated through use until they were indissolubly incorporated into formal operational thought processes as an adult.

This still does not answer the question of why some children fixate on certain aspects of their natural synaesthesia and carry these responses into adulthood, while others do not. It would be informative to follow a group of children from pre-school years into adulthood, 
and evaluate the decrease in synaesthesia in each with regard to background, experiences, schooling, personality, and other aspects of their 1ives.

It is possible that some children do not grow out of their synaesthesia for various neurophysiological reasons. One possibility pursued in the present study is that adult synaesthesia is linked to mixed dominance in the brain. Some $65 \%$ of the synaesthetic subjects in the present study showed some evidence of mixed cerebral dominance, for example, being right-handed and left-footed, or right-handed and right-footed but left-eyed. Although no exact figures are available on the incidence of mixed dominance in the general population, its occurrence is by no means unique (Travis 1957). There is even some argument that handedness, footedness, and eyedness are at all related to cerebral dominance (Crosby; Humphrey, and Lauer 1962; Hecaen and de Ajuriaguerra 1964). Stammering and various learning difficulties have often been linked with forcing a child to use his right hand when he would be naturally left-handed. If synaesthesia is also related to mixed dominance, perhaps it is a result of some necessary adjustment on the part of the brain in an effort to achieve "normalcy".

Ornstein (1972) has pointed out that in young children hemispheric dominance is not completely developed, and both sides of the brain possess equal potentia1s.' It is interesting that as a child grows out of his syncretic period and into the period of formal operations (Piaget 1969), his hemispheric dominance becomes fixed (Penfield and Roberts 1959). 
It is possible that a synaesthetic's ability to handle symbolic information in a syncretic manner is directly related to incomplete dominance in his cerebral hemispheres.

Other results in this study include the finding that more than two-thirds of the synaesthetics studied were able to recall memories as far back as age three or younger. One subject reported memories of infancy. Although it is difficult to know how trustworthy these recollections are, it would help to have a comparable list of early memories from non-synaesthetics. No such study was made in this investigation.

There were half again as many female synaesthetics, whereas there were slightly more male than female non-synaesthetics. Although the difference is not statistically significant in this sample, it should be observed that cultural factors could operate to produce such figures, for in Western societies it is considered a feminine trait to be introspective and aesthetic, qualities which may favor the recognition in oneself of synaesthetic responses. Males are often encouraged to be more action-oriented and less sensitive to colors and design.

It is difficult to determine from the results herein what, if any, neurophysiologic mechanism might produce synaesthesia in some individua1s. A further detailed study could provide additional information by including data on learning difficulties in childhood, diseases in childhood, dreaming patterns, a precise family history of each individual, and drug usage from infancy to adulthood. 


\section{TYPES OF SYNAESTHESIA}

Whatever the causes of synaesthesia, in the study at hand a wide variety of synaesthetic responses was uncovered among the positive subjects. Al1 of these types have been mentioned and described by other investigators, but the percentages seem to vary from study to study. For example, Calkins (1893) finds $15.7 \%$ of adults to have some degree of chromatism (association of colors with some other stimulus), while the present study showed an incidence of $25 \%$. No report in the literature mentions an overall incidence as high as 50\%. Possible reasons for the relatively greater percentages in the present study are several. First of all, a variety of synaesthetic types were sought, rather than concentrating on one aspect, such as color-hearing. Secondly, the subjects were made to understand through numerous examples exactly what was being asked of them, and were given ample time to examine their own minds. Thirdly, no value was attached to the possession of a synaesthetic trait, either positive or negative, and the subjects felt free to answer honestly.

Nevertheless, an incidence of $50 \%$ is somewhat higher than the expected value for adults $(20-25 \%)$, even under these favorable testing conditions (Wundram 1968-71), and it is possible that the age of the subjects is a factor. Perhaps some children do not lose their natural synaesthesia until after the teen years. If this is so, we might expect. to find a decreased incidence if this same group were examined ten years from now. One subject reported that her mother was synaesthetic until her marriage at age 19. Another reported that he used to be more 
synaesthetic, but could recal1 it on $1 \hat{y}$ in memory at his present age, or under the influence of marijuana.

The questions raised in this investigation are numerous and suggest several approaches for future research. In all cases, larger samples from more varied cultural and economic backgrounds would be desirable, as well as greater detail in interviewing and more follow-up studies. Perhaps then more information could be gathered to apply to the question of the relationship between culture and human thought processes. 


\section{Chapter VII}

\section{CONCLUSTONS}

The investigation described herein has attempted to determine whether or not cultural background--in this case socio-economic class-has any bearing on the incidence of synaesthesia in a given population. The results of this study suggest that the occurrence of synaesthesia is not related to class. What it is related to, and what its possible causes are, cannot be determined conclusively from the observations made, although the findings herein suggest that synaesthesia is strongly associated with incomplete cerebral dominance. The questions raised by this study of fer suggestions for future research into the problem. 


\section{REFERENCES}

Bruner, J.S.

1965 On knowing: essays for the left hand. New York, Atheneum. Bruner, J. S.

1967 Studies in cognitive growth. New York, Wiley.

Bruner, J. S., P. M, Greenfield and R. R. Oliver

1966 Studies in cognitive growth. New York, Wiley.

Calkins, M. W.

1893 A statistical study of pseudochromaesthesia and mental forms. Am. J. Psychol., 5:439-464.

Chapple, E.

- 1970 Culture and biological man. New York, "Holt, Rinehart and Winston.

Cole, M., J. Gay, J. Glick and D. Sharp

1971 Cultural context of learning and thinking. New York, Basic Books.

Crosby, E. C., T. Humphrey and E. W. Lauer

1962 Correlative anatomy of the nervous system. New York, The Macmillan Company.

Entwisle, D. R.

1966 Word association of young children. Baltimore, Johns Hopkins Press.

Galton, F.

1883 Inquiries into human faculty and its development. London, Everyman. 
Hecaen, H. and J. deAjuriaguerra

1964 Left-handedness. Manual superiority and cerebral dominance. New York, Grune and Stratton.

Hollingshead, A. B.

1957 Two factor index of social position. Dept. of Sociology, Yale University, New Haven, Conn. mimeo.

Horowitz, M. J.

1970 Image formation and cognition. New York, Appleton-CenturyCrofts.

Karwoski, T. F., and H. S. Odbert

1938 Color-music. Psychological Monographs, 50:1-60.

Kerr, M: and T. H. Pear

1932 Synaesthetic factors in judging the voice. Brit. J. Psychol., 23:167-170.

Langfield, H. S.

1914 Note on a case of chromaesthesia. Psychol. Bu11., 11:113-114. Lee, $D$.

1950 Codifications of reality: lineal and nonlineal. Psychosomatic Med., 12:89-97.

Luria, A. R.

1966 Higher cortical functions in man; trans. by B. Haigh. New York, Basic Books.

Luria, A. R.

1968 The mind of a mnemonist, trans, by L. Solotaroff. New York, Basic Books.

Myers, C. S.

1911 A case of synaesthesia. Brit. J. Psycho1., 4:228-238.

Ornstein, R. E.

1972 The psychology of consciousness. San Francisco, W. H. Freeman. 
Paivio, A.

1971 Imagery and verbal processes. New York, Holt, Rinehart and Winston.

Pacjak, V.

1970 Verbal synaesthesiae of colors, emotions, and days of the week. Verbal Learning and Verbal Behavior, 9:619-627.

Peele, T. L.

1961 The neuroanatomic basis for clinical neurology. New York, McGraw-Hill.

Penfield, W. and L. Roberts

1959 Speech and brain mechanisms. Princeton, Princeton University Press.

Piaget, J.

1969 Studies in cognitive development, ed. by D. Elkind and J. H. Flave11. New York, Oxford University Press.

Piaget, J. and $B$. Inhelder

1971 Mental imagery in the child, trans. by P. A. Chilton. New York, Basic Books.

Révész, G.

1922 Uber audition coloree. Z. f. andew. Psycho1., 21.

Schilder, $P$.

1942 Mind: 'perception and thought in their constructive aspects. New York, Columbia University Press.

Simpson, L. and P. McKellar

1955 Types of synaesthesia. J. Mental Sci., 101:141-147.

Slobin, D. I.

1972 They learn the same way all around the world.

Psychology Today, July (1972): 71-82. 
Wadstorth, B. J.

1971 Piaget's theory of cognitive development. New York, David Mckay $\mathrm{C}_{0}$., Inc.

Wa11ace, A. F. C.

1970 Culture and personality. New York, Random House.

Watson, R. I.

1965 The psychology of the child. New York, John Wiley and Sons.

Werner, H.

1957 Comparative psychology of mental development. New York, International Universities Press.

Wundram, I. J.

1968-1971 Unpublished observations. 


\section{APPENDIX A}

\section{INITIAL SURVEY QUESTIONNAIRE FORM}

(Copies given to subjects had a blank page appended on which they described their own personal synaesthesia, if any.) 


\section{STUDY OF COGNITIVE STYLES}

I. DEMOGRAPHIC DATA:

1. Name:

2. Date of Birth:

3. Address:

4. Phone:

5. Sex: M F

II. FAMILY HISTORY:

A. Family of Origin:

6. Father now living ___ dead

7. Educational attainment of father:

8. Occupation of father:

9. Mother now living dead

10. Educational attainment of mother:

11. Occupation of mother:

12: Marital status of parents during your childhood: married___ separated____ divorced ____ unmarried other (explain)

B. Current Family:

13. Same as above: Yes. No

14. Other (specify):

C. Siblings:

15. Number of

16. Number of brothers older younger

17. Nunber of sisters older younger 
APPENDIX B

GROUP QUESTIONING PROCEDURE

(A guide to the oral administration of the initial interview.) 


\section{GROUP QUESTIONING PROCEDURE - SYNAESTHESIA SURVEY}

We are administering this survey as part of a study of the different ways individuals perceive the world around them. We are becoming more and more aware of the fact that each person has his own individual way of thinking, his orn personal cognitive style, which makes him unique. It took us a long time to realize this, because we all speak the same language, and thus we used to assume that because we all speak alike, we all think alike. Nevertheless, in spite of all the things we have in common, like speaking the same language, each of us thinks just a little bit differently from everyone else.

One of these ways of thinking, or cognitive styles, is called "synaesthesia". The word means "together-sensing", and describes a phenomenon whereby a person experiences two sensations at once, such as seeing colors with the notes of the musical scale, or seeing colors associated with the letters of the alphabet. Not everyone does this, of course. And there is no particular advantage or disadvantage that we know of connected with this phenomenon. It's just another way of thinking.

There are several features of synaesthesia which are important. The first is that the response is always the same for the individual. If he sees colors with the letters of the alphabet, they are always the same. For example, $A$ is always red, $B$ is always brown, $S$ is always yellow, and so on. In addition, the color is an inseparable part of the 
letter; one does not see a flash of yellow when thinking of the letter "S", but rather, S itself is yellow. Another aspect of synaesthesia that is important is that the individual has done this all his 1 ife, as long as he can remember. A has always been red, $B$ has always been brown, and so on.

I'd like to ask the members of the class: Do any of you see the letters of the alphabet in color? If so, I'd like you to write down what you see -- not necessarily the whole alphabet, but just enough to convey the idea (unless you'd prefer to write it al1 down). Are the letters that you see capitals or lower-case? Remember, anything you write down must be something that happens every time you think of the letters of the alphabet, and has happened that way ever since you can remember. Don't try to farce any associations that you don't naturally have. With synaesthesia, either you do or you don't. And you'li know if you do.

Again, when you think of the letters of the alphabet, how are they arranged? For example, are they all in a straight line, or in rows, or columns perhaps?

Maybe there is some other sensation that, for you, goes with certain letters of the alphabet. For example, for some people $\mathrm{C}$ may be salty-tasting, or $M$ may smel1 sweet. 
Let's try some examples othei than letters of the alphabet. (Repeat above questioning procedure for the following:)

- days of the week

- months of the year

- years or centuries of time

- numbers

- notes of the musical scale

(Remind students periodically that the response must be consistent, and that it must have been present since childhood.)

Perhaps some of you have a type of synaesthesia that we've left out. After all these examples, you may be able to recall something in the way you think that might, fif in with what we've been talking about.

(Encourage class to offer possible synaesthetic responses they may have, and to ask questions.) 
APPENDIX $C$

PERSONAL INTERVIEW

(Form for second, individual interviews) 
Name:

PERSONAL INTERVIEW

Further description of synaesthetic response:

Earliest childhood memory:

(Âge:

\footnotetext{
.
} 
APPENDIX D

HOLLINGSHEAD'S TWO FACTOR INDEX OF SOCIAL POSITION 
TWO FACTOR INDEX OF SOCIAL POSITION

From: August B. Hollingshead

A. The Occupational Scale

1. Higher Executives, Proprietors of Large Concerns, and Major Professionals

a. Higher Executives

Bank Presidents; Vice-Presidents

Judges (Superior Courts)

Large Business, e.g., Directors,

Presidents, Vice-Presidents,

Assistant Vice-Presidents,

Executive Secretary,

Treasurer.

Military, Commissioned Officers, Major

and above, Officials of the Executive

Branch of Government, Federa1,

State, Loca1, e.g., Mayor, City

Manager, City Plan Director,

Internal Revenue Directors.

Research Directors, Large Firms

b. Large Proprietors (Value over $\$ 100,000)$

Brokers

Contractors

c. Major Professiona $1 \mathrm{~s}$

Accountants (C.P.A.)

Actuaries

Agronomists

Architects

Artists, Portrait

Astronomers

Auditors

Bacteriologists

Chemical Engineers

Chemists

Clergyman (Professionally Trained)

Dentists
Dairy Owners

Lumber Dealers

Economists

Engineers (College Grad.)

Foresters

Geologists

Lawyers

Metallurgists

Physicians

Physicists, Research

Psychologists, Practicing

Symphony Conductor

Teachers, University, College

Veterinarians (Veterinary Surgeons)

2. Business Managers, Proprietors of Medium Sized Businesses, and Lesser Professionals.

a. Business Managers in Large Concerns

Advertising Directors

Branch Managers

Brokerage Salesmen

District Managers

Executive Assistants

Executive Managers, Govt. Officials, minor, e.g., Internal Revenue Agents Farm Managers
Office Managers

Personnel Managers

Police Chief, Sheriff

Postmaster

Production Managers

Sales Engineers

Sales Managers, National Concerns

Sales Managers (Over $\$ 100,000)$ 
b. Proprietors or Medium Businesses (Value $\$ 35,000-\$ 100,000)$

Advertising Owners $(-\$ 100,000)$

Clothing Store Owners $(-\$ 100,000)$

Contractors $(-\$ 100,000)$

Express Company Aruer:s $(-\$ 100,000)$

Fruits, Wholesale $(-\$ 100,000)$

Furniture Business $(-\$ 100,000)$

Jevelers $(-\$ 100,000)$

Jabor Relations Consultants

c. Lesser Professionals

Accountants (not C.P.A.)

Chiropodists

Chiropractors

Correction Officers

Director of Community House

Engineers (not College grad.)

Finance Writers

Health Educators

Librarians
Manufacturer's Representatives

Poultry Business $(-\$ 100,000)$

Purchasing Managers

Rea1 Estate Brokers $(-\$ 100,000)$

Rug Business $(-\$ 100,000)$

Store Owners $(-\$ 100,000)$

Theater Owners $(-\$ 100,000)$

Military, Commissioned Officers, Lts., Captains

Musicians (Symphony Orchestra)

Nurses

Opticians

Pharmacists

Public Health Officers (M.P.H.)

Research Assistants, University (full-time)

Socia1 Workers

Teachers (elementary and high)

3. Administrative Personne1, Small Independent Businesses, and Minor Professionals

a. Administrative Personne1

Adjusters, insurance

Advertising Agents

Chief Clerks.

Credit Managers

Insurance Agents

Managers, Department Stores

Passenger Agents--R.R.

Private Secretaries

Purchasing Agents

Sales Representatives
Section Heads, Federal, State, and

Loca 1 Government Offices

Section Heads, Large Businesses

and Industries

Service Managers

Shop Managers

Store Managers (Chain)

Traffic Managers

b. Sma11 Business Owners $(\$ 6,000-\$ 35,000)$

Art Gallery

Auto Accessories

Awnings

Bakery

Beauty Shop

Boatyard

Brokerage, insurance

Car Dealers

Cattle Dealers

Cigarette Machines
Food Equipment

Food Products

Foundry

Funeral Directors

Furniture

Garage

Gas Station

Glassware

Grocery-General

Hote1 Proprietors 
b. Sma11 Business Otners (Cont'd.)

Cleaning Shop
Clothing
Coal Business
Convalescent
Decorating
Dog Supplies
Dry Goods
Electrica1 Cont
Engraving Bus
Feed
Finance Co.,
Fire Extinguist
5 \& 10
Florist
Shoe
Shoe Repairs
Signs
Tavern
Taxi Company
Tire Shop

c. Semi Professiona 1s

Actors and Showmen

Army M/Sgt; Navy C.P.O.

Artists, Commercial

Appraisers (estimators)

Clergymen (not professionally trained)

Concern Managers

Deputy Sheriffs

Dispatchers, R.R. Train

I.B.M. Programmers

Interior Decorators

Interpreters, Court

Laboratory Assistants

Landscape $\mathrm{Planners}$

d. Farmers
Inst. of Music

Jewelry

Machinery Brokers

Manufacturing

Monuments

Package Store (1iquor)

Painting Contracting

Pluinbing

Poultry. Producers

Pub1icity \& Public Relations

Rea1 Estate

Records \& Radios

Restaurant

Roofing Contractor

Trucking

Trucks and Tractors

Upholstery

Wholesale Outlets

Window Shades

Farm Owners $(\$ 25,000-\$ 35,000)$

4. Clerical and Sales Workers, Technicians, and Owners of Little Businesses (Value under $\$ 6,000)$

a. Clerical and Sales Workers

Bank Clerks and Tellers

Bi11 Collectors

Bookkeepers

Business Machine Operators, Offices

Claims Examiners

Clerical or Stenographic

Conductors, R。R.

Employment Interviewers
Morticians

Ora1 Hygienists

Photographers

Physio-therapists

Piano Teachers

Radio, T.V. Announcers

Reporters, Court

Reporters, Newspaper

Surveyors

Title Searchers

Tool Designers

Travel Agents

Yard Masters, R.R. 
b. Technicians

Camp Counselors

Dental Technicians

Draftsmen

Driving Teachers

Expeditor, Factory

Experimental Tester

Instructors, Telephone Co., Factory

Inspectors, Weights, Sanitary

Inspectors, R.R., Factory

Investigators

Laboratory Technicians

Locomotive Engineers

c. Owners of Little Businesses

Flower Shop $(\$ 3,000-\$ 6,000)$

Newsstand $(\$ 3,000-\$ 6,000)$

Tailor Shop $(\$ 3,000-\$ 6,000)$

d. Farmers

Owners $(\$ 10,000-\$ 20,000)$

5. Skilled Manual Employees

Adjusters, Typewriter

Auto Body Repairers

Bakers

Barbers

Blacksmiths

Bookbinders

Boilermakers

Brakemen, R.R.

Brewers

Bulldozer Operators

Butchers

Cabinet Makers

Carpenters

Casters (Founders)

Cement Finishers

Cheese Makers

Chefs

Compositors

Diemakers

Diesel Engine Repair \& Maintenance (trained)

Diesel Shovel Operators

Electricians

E1ectrotypists

Engravers

Exterminators
Operators, P.B.X.

Proofreaders

Safety Supervisors

Supervisors of Maintenance

Technical Assistants

Telephone Co. Supervisors

Timekeepers

Tower Operators, R.R.

Truck Dispatchers

Window Trimmers (store)
Loom Fixers

Lumber jacks

Machinj.sts (trained)

Maintenance Foremen

Installers, Electrical Appliances

Masons

Masseurs

Mechanics (trained)

Millwrights

Moulders (trained).

Painters

Paperhangers

Patrolmen, R.R.

Pattern and Model Makers

Piano Builders

Piano Tuners

Plumbers

Policemen, City

Postmen

Printers

Radio, T.V., Maintenance

Repairmen, Home Appliances

Riggers

Rope Splicers 
5. Skilled Manual Employees (Cont'd.)

$\begin{array}{ll}\text { Fitters, Gas, Steam } & \text { Sheetmetal Workers (trained) } \\ \text { Firemen, City } & \text { Shipsmiths } \\ \text { Firemen, R.R. } & \text { Shoe Repairmen (trained) } \\ \text { Foremen, Construction, Dairy } & \text { Stationary Engineers (1icensed) } \\ \text { Gardeners, Landscape (trained) } & \text { Stewards, Club } \\ \text { Glassblowers } & \text { Switchmen, R.R. } \\ \text { Glaziers } & \text { Tailors (trained) } \\ \text { Gunsmiths } & \text { Teletype Operators } \\ \text { Gauge Makers } & \text { Toolmakers } \\ \text { Hair Stylists } & \text { Track Supervisors, R。R. } \\ \text { Heat Treaters } & \text { Tractor-Trailer Trans. } \\ \text { Horticulturists } & \text { Typographers } \\ \text { Linemen, Utility } & \text { Upholsterers (trained) } \\ \text { Linoleurn Layers (trained) } & \text { Watchmakers } \\ \text { Linotype Operators } & \text { Weavers } \\ \text { Lithographers } & \text { Welders } \\ \text { Locksmiths } & \text { Yard Supervisors, R.R. }\end{array}$

\section{Small Farmers}

Owners (under $\$ 10,000$ )

Tenants who own farm equipment

\section{Machine Operators and Semi-Skilled Employees}

Aides, Hospital

Apprentices, Electricians, Printers, Steamfitters, Toolmakers

Assembly Line Workers

Bartenders

Bingo Tenders

Building Superintendents (Cust.)

Bus Drivers

Checkers

Clay Cutters

Coin Nachine Fillers

Cooks, Short Order

Delivery Men

Dressmakers, Machine

Drill Press Operators

Duplicator Machine Operators

Elevator Operators

Enlisted Men, Military Services

Filers, Benders, Buffers

Foundry Workers

Garage and Gas Station Assistants

Greenhouse Workers

Guards, Doorkeepers, Watchmen

Hairdressers
Paper Rolling Machine Operators

Photostat Machine Operators

Practical Nurses

Pressers, Clothing

Pump Operators

Receivers and Checkers

Roofers

Set-up Men, Factories

Shapers

Signalmen, R, R.

Solderers, Factory

Sprayers, Paint

Steelworkers (not skilled)

Stranders, Wire Machines

Strippers, Rubber Factory

Taxi Drivers

Testers

Timers

Tire Moulders

Trainmen, R.R.

Truck Drivers; Genera 1

Waiters-Waitresses ("Better Places")

Weighers

Welders, Spot 
6. Machine Operators and Semi-Skilled Eimployees (Cónt'd.)

Hous ekeepers

Meat Cutters and Packers

Meter Readers

Operators, Factory Machines

Oiler, R.R.
Winders, Machine

Wiredrawers, Machine

Wine Bottlers

Wood Workers; Machine.

Wrappers, Stores and Factories

\section{Farmers}

Smaller Tenants who own little equipment.

\section{Unskilled Employees}

Amusement Park Workers (Bowling Aileys, Pool Rooms)

Ash Removers

Attendants, Parking Lots

Cafeteria Workers

Car Cleaners, R.R.

Car Helpers, R.R. .

Carriers, Coal

Countermen

Da iry Workers

Deck Hands

Laborers, Construction

Domestics

Farm Helpers:

Fishermen (clam diggers)

Freight Handlers

Garbage Collectors

Grave Diggers

Hod Carriers

Hog Killers

Hospital Workers, unspecified

Hostlers, R.R.

Janitors, Sweepers

Laborers, Unspecified

Stagehands

Laundrey Workers

Messengers

Platform Man, R.R.

Peddlers

Porters

Roofer's Helpers

Shirt Folders

Shoe Shiners

Sorters, Rag and Salvage

Stevedores

Stock Handlers

Street Cleaners

Unskilled Factory Workers

Truckmen, R.R.

Waitresses-- "Hash Houses"

Washers, Cars.

'Window Cleaners

Woodchoppers

Relief, Publicc, Private

Unemployed-(no occupation)

\section{Farmers}

Share Croppers 


\section{B. The Educational Scale}

The educational scale is premised upon the assumption that men and women who possess similar educations will tend to have similar tastes and similar attitudes, and they will also tend to exhibit similar behavior patterns. The educational scale is divided into seven positions:

(1) Graduate Professional Training. (Persons who complete a recognized professional course leading to a graduate degree are given scores of 1).

(2) Standard College or University Graduation. (All individuals who complete a four-year college or university course leading to a recognized college degree are assigned the same scores. No differentiation is made between state universities, or private colleges:).

(3) Partial College Training. (Individuals who complete at least one year but not a full college course are assigned this position. Most individuals in this category complete from one to three years of college.)

(4) High School Graduates. (A11 secondary school graduates whether from a private preparatory school, a public school, a grade school, or a parochial high school, are assigned the same scale value.)

(5) Partial High School. (Individuals who complete the tenth or the cleventh grades, but do not complete high school are given this score.)

(6) Junior High School. (Individuals who complete the seventh grade through the ninth grade are given this position.).

(7) Less Than Seven Years of School. (Individuals who do not complete the seventh grade are given the same scores irrespective of the amount of education they receive.)

C. Calculation of Index of Social Position Score:

Factor

Occupation

Education

Social Class

$I$

II

III

IV
Scale Score

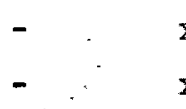

Index of Social Position Score

Range of Computed Scores.

$11-17$

$18-27$

$28-43$

$44 \div 60$

$61-77$
Score $X$ Weight

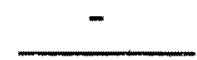

